Article

\title{
Carob Seeds: Food Waste or Source of Bioactive Compounds?
}

\author{
Debora Santonocito ${ }^{1,+}$, Giuseppe Granata ${ }^{2,+}{ }^{\mathbb{D}}$, Corrada Geraci ${ }^{2}$ (D) Annamaria Panico ${ }^{1}$, \\ Edy Angela Siciliano ${ }^{1}$, Giuseppina Raciti ${ }^{1}$ and Carmelo Puglia ${ }^{1, *(1)}$ \\ 1 Department of Drug Sciences, University of Catania, 95125 Catania, Italy; \\ debora.santonocito@outlook.it (D.S.); panico@unict.it (A.P.); edysiciliano@hotmail.it (E.A.S.); \\ racitigi@unict.it (G.R.) \\ 2 Istituto Chimica Biomolecolare-C.N.R., Via Paolo Gaifami 18, 95126 Catania, Italy; \\ giuseppe.granata@icb.cnr.it (G.G.); corrada.geraci@icb.cnr.it (C.G.) \\ * Correspondence: capuglia@unict.it \\ + These authors contributed equally to this work.
}

Received: 26 October 2020; Accepted: 11 November 2020; Published: 13 November 2020

check for updates

\begin{abstract}
Background: For centuries, carob fruit has been used in the food field, while carob seeds have been mainly considered as food waste. Nowadays, there has been considerable attention toward the recovery of the waste plant matrices as possible sources of functional compounds with health properties. Therefore, our goal was to evaluate the health properties of carob seed extracts, and to study the effects of the ripening process on the chemical composition of the extracts. (2) Methods: After the mechanical separation of seeds from carob fruit, an ultrasound-assisted extraction (UAE) was performed to maximize and preserve the quality of bioactive compounds. Seed extracts were characterized by high-performance liquid chromatography (HPLC) and liquid chromatography/mass spectrometry (LC/MS) for the content of bioactive polyphenols, and were finally analyzed by oxygen radical absorbance capacity (ORAC), NO Scavenger (NO) and advanced glyoxidation end products (AGEs) assays, in order to estimate the antioxidant potential of the active compounds. (3) Results: Although both seed extracts of carob unripe (CAR-UR) and ripe (CAR-R) showed an interesting antioxidant activity, CAR-R had greater activity due to the procyanidins content. (4) Conclusions: Based on the obtained results, carob seed extracts could be regarded as interesting source of bioactive antioxidant compounds for a potential application in nutraceutical and food supplement fields.
\end{abstract}

Keywords: carob fruit; seed carob; food waste; ORAC; polyphenols

\section{Introduction}

Carob (Ceratonia siliqua L.) is an evergreen tree widely cultivated in the Mediterranean area. It belongs to the Leguminosae family and its scientific name derives from the Greek word "kera", due to the keratomorphic shape of the fruit, and the Latin word "siliqua", related to the hardness and shape of the pods [1,2]. The carob fruit (bean) is called pod and consists of two parts: the seeds $(10 \%)$ and the pulp (90\%). The pulp comprises a leathery outer layer (pericarp) and a softer inner region (mesocarp) where the seeds are found; meanwhile, the seeds are composed of three layers: shell, endosperm and embryo. Seeds are brown, hard, $10 \mathrm{~mm}$ long and with a weight of about $0.2 \mathrm{~g}$ per seed [3-5]. Due to the homogeneity in weight of the seeds, it is popularly believed that the carat, the unit of weight for gemstones, is derived from the carob seeds [6].

Carob pulp contains numerous bioactive compounds such as sugars, cyclitols, polyphenols, amino acids, fibers and minerals, while the composition of carob seeds includes gum, polyphenols and proteins [1]. Due to the chemical composition, carob exhibits a powerful antioxidant activity, 
and possesses many valuable therapeutic functions, such as lipid-lowering [7], anti-cardiovascular, anti-proliferative [8,9] and nephroprotective properties [10]. Furthermore, during the ripening of the fruit, many biochemical reactions occur with consequent modifications of the final characteristics of ripe fruit $[11,12]$.

In Sicily, for centuries, the carob pod has been used in the food field, in particular in homemade pastry, due to the high sugar content $(>50 \%)$ [13]. In fact, the primary seedless pod products are flour and syrup, which can be used as a chocolate or cocoa substitute. The seed exclusion from the industrial productivity is due to the differences of fat and carbohydrate composition between carob pulp and seeds, which modifies the sweet taste of the carob flour and syrup. Furthermore, these differences are shown also in terms of antioxidant activity [3]. The main marketed product carob seed based is the locust bean gum (LBG), a natural hydrocolloid, widely used in food industry as stabilizer and thickener [14]. Therefore, in the pharmaceutical field the seeds remain as a "food by-product", a technical term to define a "food waste".

Nowadays, there has been considerable attention toward the recovery of the waste plant matrices as possible sources of functional compounds with health properties [15]. Therefore, the purpose of the present work is to evaluate the health properties of carob seed extract and to study the effects of the ripening process on the chemical composition of the extract. In particular, we evaluated unripe (CAR-UR) and ripe (CAR-R) carob seed extracts to understand how the phytochemical composition changed during ripening process. In order to propose a suitable valorization of this food industry by-product an ultrasound-assisted extraction (UAE) technique has been used. This technique is considered an environmentally friendly extraction process, due to the use of generally recognized as safe (GRAS) solvents and the reduction of processing and residence times. Therefore, it improves the quality of bioactive product by providing higher recovery yields compared to classical extractions, and preserving also target activities of the extracts.

\section{Materials and Methods}

\subsection{Chemical Reagents}

Ethanol, 2,2'-Azobis(2-methylpropionamidine) dihydrochloride (AAPH), fluorescein (FL), 6-Hydroxy-2,5,7,8-tetramethylchroman-2-carboxylic acid (Trolox), aminoguanidine carbonate (AMG), bovine serum albumin (BSA), D-fructose, sodium nitroprusside and Griess reagent ( $1 \%$ dihydrochloride sulphanylamide and $0.1 \%$ naphthylethylenediamine (NED) dihydrochloride in $5 \%$ of hydrochloric acid), sodium azide, curcumin and analytical standards were purchased from Sigma-Aldrich srl (Milan, Italy). Water LC-MS Grade LiChrosolv and formic acid were obtained from Merck (Milan, Italy), acetonitrile gradient grade for high-performance liquid chromatography (HPLC) HiPerSolv Chromanorm from VWR Chemicals (Milan, Italy).

\subsection{Plant Materials}

Carob pods of Ceratonia siliqua L. were collected during June-August in the eastern parts of Sicily (Catania, Italy), where they naturally grow, and were identified by Professor C. Puglia, University of Catania (Italy). Samples were stored in freezer to stop ripening and analyzed within one month of collection. Seeds ( $10 \mathrm{~g}$ ) were separated from the unripe (CAR-UR; UR) and ripe (CAR-R; R) fruits and then dried at different times $(24 \mathrm{~h}, 48 \mathrm{~h}$ and $72 \mathrm{~h} ; \mathbf{1}, 2$ and 3$)$ at $50^{\circ} \mathrm{C}$. Finally, they were crushed in a mechanical mill, and the resulting powder was extracted as described below.

\subsection{Ultrasound-Assisted Extraction (UAE) Technique}

The powder samples of carob seeds were extracted with a mixture of ethanol/water $(40: 60, v / v)$ using an ultrasonic processor (UP 400 S, Dr. Hielscher GmbH, Stuttgart, Germany) for 20 min [16]. The temperature of the extraction process was stabilized by using an ice-bath. Subsequently, the extracts were stirred at room temperature for $3 \mathrm{~h}$ (1st extraction; $\mathbf{x}$ ) and settled overnight. The supernatant was 
collected, filtered through a paper filter, concentrated under vacuum to remove ethanol and lyophilized (Lio 5P-Pascal SRL, Milan, Italy).

In order to maximize the extraction process, the residual precipitate was further extracted with the hydro-alcoholic solution for $6 \mathrm{~h}$ under magnetic stirring and settled overnight (2nd extraction; y). Finally, the obtained supernatant was subjected to the same experimental procedure and the plant matrix was thrown away.

\subsection{Analytical Determination}

A total of $1 \mathrm{mg}$ of the seed extracts of carob unripe (CAR-UR) and ripe (CAR-R) were treated with $600 \mu \mathrm{L}$ of water/MeOH $(5: 1, v / v)$ solution. The resulting mixtures were centrifuged at $3500 \times g$ for $5 \mathrm{~min}$. The supernatants were analyzed by HPLC-UV and liquid chromatography/mass spectrometry (LC/MS), for quantitative and qualitative determination of phenolic compounds, respectively. Dionex HPLC system (P680 pump, ASI-100 autosampler, UVD170U detector, Dionex, Milan, Italy) and Phenomenex Luna $5 \mu \mathrm{m} \mathrm{C18}$ reverse-phase column $(250 \times 4.6 \mathrm{~mm})$, thermostated at $35^{\circ} \mathrm{C}$, were used. The mobile phase was composed of $0.1 \%$ formic acid in $\mathrm{CH}_{3} \mathrm{CN}(\mathrm{A})$ and $0.1 \%$ formic acid in water (B). The elution program was: $5 \%$ A for $5 \mathrm{~min}$, from $5 \%$ A to $15 \%$ over $10 \mathrm{~min}, 15 \%$ A for $5 \mathrm{~min}, 15 \%$ A to $20 \%$ over $5 \mathrm{~min}$, $20 \%$ A to $25 \%$ over $10 \mathrm{~min}, 25 \%$ A to $35 \%$ over $10 \mathrm{~min}, 35 \%$ A to $50 \%$ over $10 \mathrm{~min}$, flow $0.5 \mathrm{~mL} / \mathrm{min}$. Chromatograms were recorded at $\lambda=370 \mathrm{~nm}$ and $280 \mathrm{~nm}$, and peak areas were used to determinate the amounts of phenolic compounds. The quantities, expressed in $\mu \mathrm{g}$ per mg of extract, were derived by standard calibration curve of following compounds: gallic acid $\left(R^{2}=0.997\right)$, quercetin 3-O-glucoside $\left(R^{2}=0.9995\right)$; quercetin 3-O-ramnoside $\left(R^{2}=0.997\right)$, catechin $\left(R^{2}=0.9993\right)$. For identified polyphenols for which standard substances were not available, the quantities were calculated in comparison with available standards containing the same aglycon [17] or similar structure. All analyses were performed at least three times, and the results were expressed as a mean \pm standard deviation.

LC/MS analysis to identify the main phenolic compounds was performed by UltiMate 3000 UHPLC instrument (Thermo Fisher Scientific, Milan, Italy), equipped with Thermo Scientific Exactive Plus Orbitrap MS (Thermo Fisher Scientific) and using a heated electrospray ionization (HESI II) interface (Thermo Fisher Scientific). The column and elution program were the same of HPLC analysis. ESI-mass spectra were recorded in negative ion mode under the following conditions: heater $300^{\circ} \mathrm{C}$; capillary temperature $300{ }^{\circ} \mathrm{C}$; nebulizer gas (nitrogen) with a flow rate of 60 arbitrary units; source voltage $-3.5 \mathrm{kV}$; capillary voltage $-82.5 \mathrm{~V}$; tube lens voltage $-150 \mathrm{~V}$. Data acquisition and analysis were performed using the "Xcalibur software (Version 3.0, Thermo Fisher Scientific, Milan, Italy)

\subsection{In Vitro Studies}

\subsubsection{Antiglycation Activity}

According to the method of Derbre et al. [18] with slight modifications, we evaluated the inhibition of fluorescence produced by AGE formation through Maillard reaction. Briefly, as optimum AGE formation, the protein model bovine serum albumin (BSA) $(10 \mathrm{mg} / \mathrm{mL})$ was incubated with D-fructose $(0.5 \mathrm{M})$ in phosphate buffer $50 \mathrm{mM} \mathrm{pH} 7.4\left(\mathrm{NaN}_{3} 0.02 \%\right)$ to obtain positive controls. Native BSA sample was the negative control corresponding to no fluorescence AGE formation. The aminoguanidine (AMG) $(400 \mu \mathrm{g} / \mathrm{mL})$ was used as reference compounds for its AGE inhibition property [19]. The final glycated BSA solutions $(300 \mu \mathrm{L})$ alone or in presence of samples $(400 \mu \mathrm{g} / \mathrm{mL})$ were incubated at $37^{\circ} \mathrm{C}$ in a 96-well microtiter closed with their silicon lids for 7 days. The AGE fluorescence measurement $\left(\lambda_{\text {exc }} 370 \mathrm{~nm} ; \lambda_{\mathrm{em}} 440 \mathrm{~nm}\right)$ is performed using a VICTOR Wallac 1420 Multilabel Counter fluorimeter (PerkinElmer, Waltham, MA, USA). The results are reported in relative fluorescence units (RFU), and the percentage of inhibition with respect to the positive control (BSA with fructose) is calculated from the following Equation (1):

$$
\% \text { of inhibition }=[1-(\text { RFU sample/RFU }- \text { positive control })] \times 100
$$




\subsubsection{Oxygen Radical Absorbance Capacity (ORAC) Assay}

According to the method reported by Cao et al. [20-22], the antioxidant activity of CAR-UR and CAR-R was evaluated in vitro using the oxygen radical absorbance capacity (ORAC) assay. This assay evaluates the fluorescence reduction of a fluorescent probe (fluorescein solution FL, $12 \mathrm{nM}$ ) due to the action of peroxyl radicals generated by thermal decomposition of 2,2'-azobis(2-methylpropionamidine) dihydrochloride (AAPH, $100 \mathrm{mM}$ ). In the presence of an antioxidant, peroxyl radicals are scavenged and the decay of the fluorescence curve is retarded. The assay was carried out at $\mathrm{pH} 7.0$ and at $37^{\circ} \mathrm{C}$, using a VICTOR Wallac 1420 Multilabel Counters fluorimeter (Perkin Elmer, Boston, MA, USA) with a fluorescence filter (excitation $540 \mathrm{~nm}$, emission $570 \mathrm{~nm}$ ). Trolox $(12.5 \mu \mathrm{M})$ was used as the control and phosphate buffer (pH 7.0) as the blank. CAR-UR and CAR-R $(1 \mathrm{mg} / \mathrm{mL})$, were solubilized in ethanol, phosphate buffer or in their mix $(50: 50, v / v)$.

After thermostating for $30 \mathrm{~min}$ at $37^{\circ} \mathrm{C}, \mathrm{AAPH}$ was added and fluorescence measurement was begun. The fluorescence was recorded every $2 \mathrm{~min}$. All measurements were expressed in relation to the initial reading, analyzing all samples, one blank and one standard at the same time. Each measure was carried out in triplicate. The ORAC value refers to the net protection area under the quenching curve of FL in the presence of an antioxidant. The results (ORAC values) were obtained and were expressed using Trolox equivalents (TE) for $\mathrm{mg}$ of sample (TE/mg) according to Equation (2):

$$
\text { ORAC units }(T E / m g)=K\left(S_{\text {sample }}-S_{\text {blank }}\right) /\left(S_{\text {Trolox }}-S_{\text {blank }}\right)
$$

where $K$ is a sample dilution factor and $S$ is the area under the fluorescence decay curve of the sample, Trolox, or blank calculated with Origin ${ }^{\circledR} 7$ (OriginLab Corporation, Northampton, MA, USA).

\subsubsection{NO Scavenger Assay}

The ability of CAR-UR and CAR-R ( $1 \mathrm{mg} / \mathrm{mL})$, to inhibit the spontaneous NO production from an aqueous solution of sodium nitroprusside $(20 \mathrm{mM})$ at $25^{\circ} \mathrm{C}$ for $3 \mathrm{~h}$ was evaluated using a Griess reagent [23,24]. Curcumin $(100 \mu \mathrm{g} / \mathrm{mL})$ was used as reference compound, as it is a well-known molecule endowed with antioxidant activity [25-27]. Absorbance was measured at $540 \mathrm{~nm}$ with a spectrophotometer (Multiskan ${ }^{\circledR}$ EX, Thermo Scientific, Waltham, MA, USA). The percent of inhibition of NO radical production was calculated according to the following Equation (3):

$$
\% \text { of inhibition of } N O=\left[A_{0}-A_{1}\right] / A_{0} \times 100
$$

where $A_{0}$ is the absorbance of untreated sample, $A_{1}$ is the absorbance of treated samples (carob seeds).

\section{Results and Discussion}

\subsection{Ultrasound-Assisted Extraction (UAE)}

The UAE technique has been chosen for the extraction of the bioactive compounds from carob seeds. This green extraction process has been developed in order to overcome problems encountered when using conventional methods [28,29]. In fact, UAE is considered environmentally friendly, as it makes it possible to shorten processing times, to improve the product quality, to reduce the solvent amounts and, finally, to use GRAS solvents [30,31]. In addition, it is suitable for the extraction of bioactive compounds, as it provides higher recovery yields than conventional extractions and preserves the target activities of the extracts [32,33].

In order to preserve the activity of the bioactive compounds, the extraction was performed at $50^{\circ} \mathrm{C}$ for $20 \mathrm{~min}$, since it has been shown that longer extraction times lead to higher extraction yields [34].

Concerning the solvents, an ethanol: water mixture $(40: 60 v / v)$ was chosen, since it is more suitable for the ultrasound extraction of phenolic compounds $[17,35]$. 


\subsection{Qualitative and Quantitative Analyses of Bioactive Compounds from CAR-UR and CAR-R Extracts}

The qualitative analyses of principal bioactive polyphenols from carob extract were performed by LC-MS, while quantitative analyses were carried out by HPLC-UV.

In Table 1, the characteristic of distinguished compounds from CAR-UR and CAR-R extracts and corresponding tentative identities are reported. During the identification of polyphenols contained in the carob seed extracts, four different groups were distinguished: flavonols (quercetins and kaempferol derivatives), flavanols (catechins and procyanidins), gallic acid and derivatives, hydrolysable tannins. We targeted the compounds belonging to these classes, because they are biologically active natural compounds responsible for activities, impacting human health.

Table 1. Identification of phenolic compounds in the carob seed extracts.

\begin{tabular}{|c|c|c|c|c|}
\hline Phenolic Compound & Rt (min) & UV Detection $(\lambda(\mathrm{nm}))$ & {$[\mathbf{M}-\mathbf{H}]^{-}(\mathrm{m} / \mathrm{z})$} & Tentative Identification \\
\hline 1 & 10.2 & 280 & 331 & Monogalloyl-hexose \\
\hline 2 & 13.7 & 280 & 169 & Gallic acid \\
\hline 3 & 20.8 & 280 & 483 & Digalloyl-hexose \\
\hline 4 & 22.2 & 280 & 577 & Procyiandin dimer \\
\hline 5 & 22.6 & 280 & 865 & Procyiandin trimer \\
\hline 6 & 23.6 & 280 & 289 & Catechin \\
\hline 7 & 25.3 & 280 & 183 & $\begin{array}{c}\text { Gallic acid methyl } \\
\text { derivative }\end{array}$ \\
\hline 8 & 26.3 & 280 & 635 & Trigalloyl-hexose \\
\hline 9 & 31.8 & 280 & 787 & Tetragalloyl-hexose \\
\hline 10 & 34.1 & 280 & 197 & Gallic acid derivative \\
\hline 11 & 34.7 & 370 & 463 & Quercetin-hexoside \\
\hline 12 & 35.2 & 280 & 441 & Catechin isomer gallate \\
\hline 13 & 36.7 & 370 & 433 & Quercetin-pentoside \\
\hline 14 & 37.5 & 370 & 433 & Quercetin-pentoside \\
\hline 15 & 38.3 & 370 & 433 & Quercetin-pentoside \\
\hline 16 & 39.2 & 370 & 447 & Quercetin-deoxyhexoside \\
\hline 17 & 43.3 & 370 & 431 & Kaempferol-deoxyhexoside \\
\hline
\end{tabular}

\subsubsection{Flavonols}

In a sample from CAR-R extract, the quantity of flavonols is greater than CAR-UR extract (Figure 1). As regards to the drying time $(24 \mathrm{~h}, 48 \mathrm{~h}$ and $72 \mathrm{~h}$ ) of the matrix and the time of extraction ( $3 \mathrm{~h}$ and $6 \mathrm{~h}$ ), the major quantity of biocomponents is present in the samples from carob seeds dried at $24 \mathrm{~h}$ and extracted for $3 \mathrm{~h}$ (R1x with $8.8 \pm 0.3 \mu \mathrm{g} / \mathrm{mg}$ and UR1x with $2.7 \pm 0.1 \mu \mathrm{g} / \mathrm{mg}$ ). Among the different identified flavonols, quercetin-deoxyhexoxide is the most abundant in all series, reaching $5.2 \pm 0.1 \mu \mathrm{g} / \mathrm{mg}$ in the R1x sample.

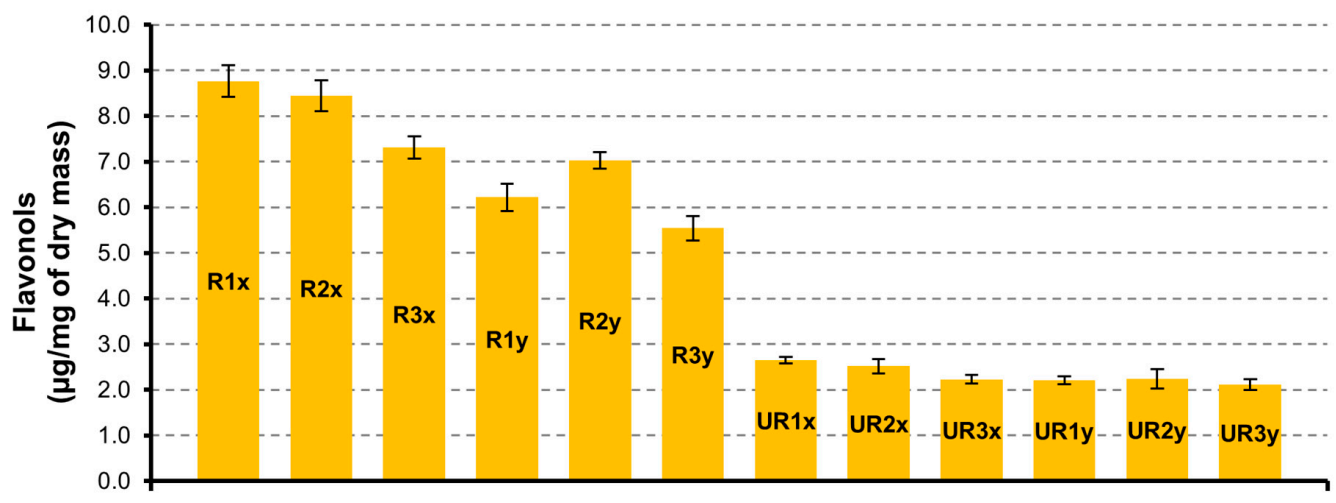

Figure 1. Flavonols quantification in CAR-R and CAR-UR extracts; 1 (24 h), 2 (48 h), and 3 (72 h) time of drying; $\mathrm{x}(3 \mathrm{~h})$ and $\mathrm{y}(6 \mathrm{~h})$ time of extraction. 


\subsubsection{Flavanols}

Catechins

Differently from flavonols, the highest content of catechin and derivatives was determined in CAR-UR extract (Figure 2). The sample UR1x obtained from matrix dried at $24 \mathrm{~h}$ and extracted for $3 \mathrm{~h}$ contains a greater quantity of catechins $(13.9 \pm 0.4 \mu \mathrm{g} / \mathrm{mg})$. In all samples the catechin is the flavanol present in larger quantities with a value of $10.8 \pm 0.3 \mu \mathrm{g} / \mathrm{mg}$ in UR1x sample.

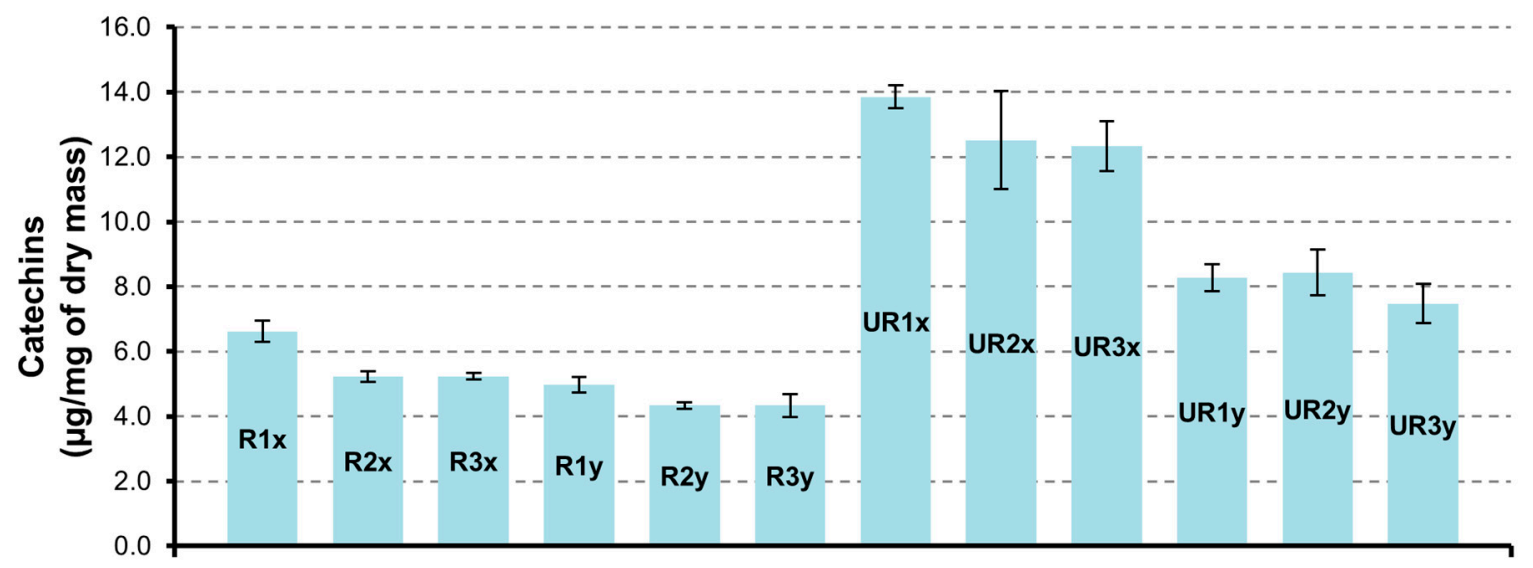

Figure 2. Catechins quantification in CAR-R and CAR-UR extracts; 1 (24 h), 2 (48 h), and 3 (72 h) time of drying; $x(3 \mathrm{~h})$ and $y(6 \mathrm{~h})$ time of extraction.

Procyanidins

Similarly, with what was observed for flavonols, the major quantity of procyanidins (Figure 3) is found in CAR-R extracts. For both series (UR and R), the samples obtained by seed extracted for $3 \mathrm{~h}$ show a more abundant content of procyanidins. Unexpectedly, the UR1y sample is less rich in procyanidins compared to the UR2y and UR3y samples obtained by a drying time of $48 \mathrm{~h}$ and $72 \mathrm{~h}$, respectively. Procyanidin dimer is the principal component of the procyanidins group, with maximum quantity of $17.4 \pm 0.5 \mu \mathrm{g} / \mathrm{mg}$ in R1x sample.

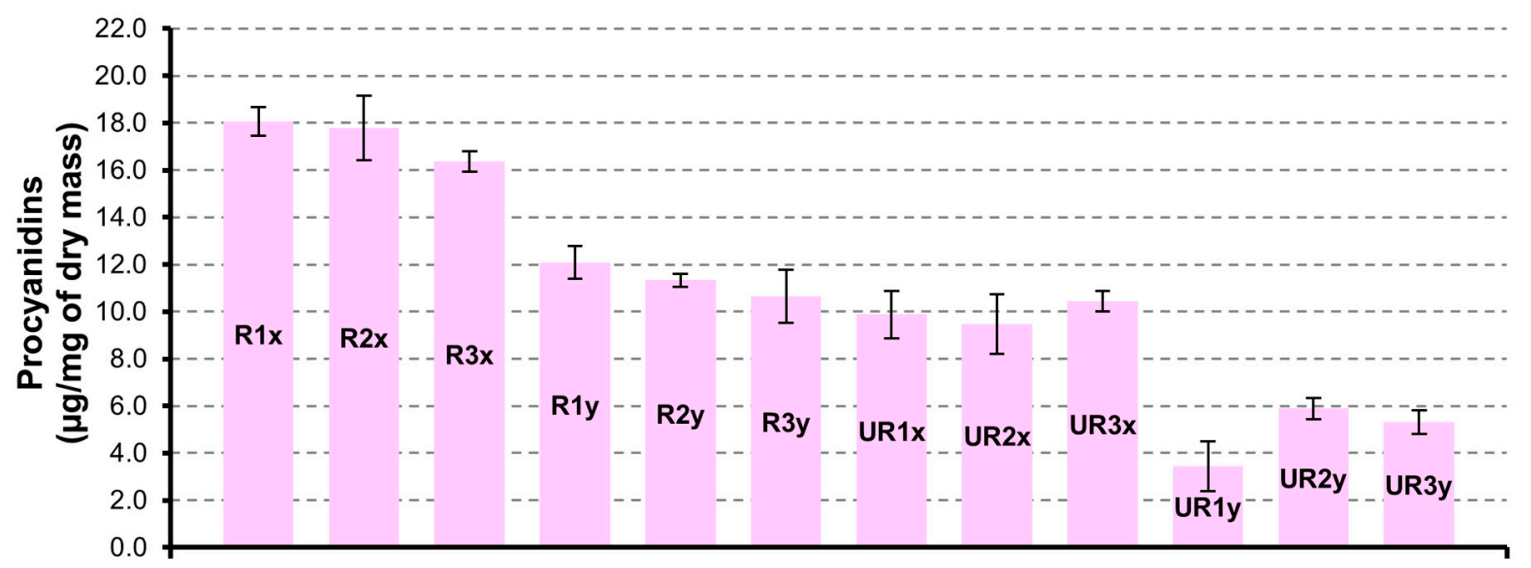

Figure 3. Procyanidins quantification in CAR-R and CAR-UR extracts; 1 (24 h), 2 (48 h) and 3 (72 h) time of drying; $x(3 \mathrm{~h})$ and $y(6 \mathrm{~h})$ time of extraction.

\subsubsection{Gallic Acid and Derivatives}

The group of gallic acid and derivatives are more abundant in CAR-UR extracts (Figure 4). The treatment of the seed matrix under conditions of higher drying time ensures a more effective 
recovery of this group of compounds. In fact, the trend is in favor of products dried for $72 \mathrm{~h}$ and samples UR3x have the highest content of gallic acid and derivatives $(25.9 \pm 1.3 \mu \mathrm{g} / \mathrm{mg})$. Instead, the extraction time for $3 \mathrm{~h}$ (x series) or $6 \mathrm{~h}$ (y series) does not significantly affect the gallic acid and derivatives quantities.



Figure 4. Gallic acid and derivatives quantification in CAR-R and CAR-UR extracts; 1 (24 h), 2 (48 h) and $3(72 \mathrm{~h})$ time of drying; $\mathrm{x}(3 \mathrm{~h})$ and $\mathrm{y}(6 \mathrm{~h})$ time of extraction.

\subsubsection{Hydrolysable Gallotannins}

The same trend observed for gallic acid and derivatives is observed for gallotannins group (Figure 5). Gallotannins are present in significant quantities in UR samples. The highest value of $100.6 \pm 5.1 \mu \mathrm{g} / \mathrm{mg}$ is present in UR3x sample (unripe seeds, dried at $72 \mathrm{~h}$ and extracted for $3 \mathrm{~h}$ ). In almost all samples, the trigalloyl-hexose is the biocomponent most abundant, reaching the value of $34.3 \pm 1.1 \mu \mathrm{g} / \mathrm{mg}$ in UR3x sample.

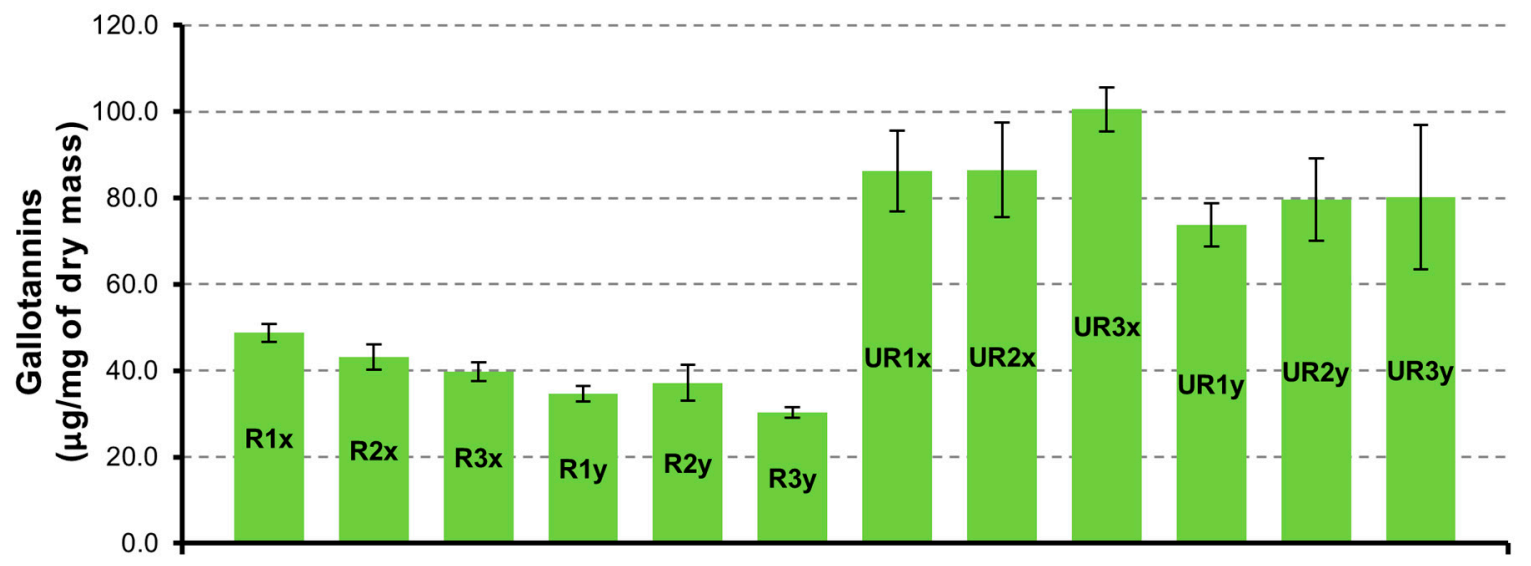

Figure 5. Gallotannins quantification in CAR-R and CAR-UR extracts 1 ( $24 \mathrm{~h}), 2$ (48 h) and 3 (72 h) time of drying; $x(3 \mathrm{~h})$ and y $(6 \mathrm{~h})$ time of extraction.

\subsection{In Vitro Studies}

\subsubsection{Anti-Glycation Activity}

Advanced glyoxidation end products (AGEs) are extensively studied as reporters of oxidative and glycooxidative damages. This condition, related to various diseases based on oxidative stress, is characterized by an increased amount of AGE contained in the tissues and body fluids, and this process, due to the formation of irreversibly fluorescent macroprotein derivatives called AGEs, occurs through the Maillard reaction, polyols pathway or lipoperoxidation. AGEs are considered reliable biomarkers 
of oxidative damages, and have been recognized as important pathogenetic factors of some oxidative diseases. AGEs are now considered promising drug targets, therefore researchers' attention is focused on the development of natural/synthetic strategies capable of preventing, reducing or removing these protein oxidation products [36].

In the present work, we evaluated the inhibitory effects of CAR-R and CAR-UR extracts on the formation of fluorescent AGEs. The scientific literature, in fact, outlines the protective effect of phytochemicals, such as polyphenols, against advanced glycation of proteins [36]. From the results obtained, it seems that the effect of the extraction times $(24 \mathrm{~h}, 48 \mathrm{~h}$ and $72 \mathrm{~h}$ ) did not play a pivotal role in increasing the inhibitory effect of both CAR-R and CAR-UR extracts; similarly, no significant differences were found, in terms of inhibitory effect on AGE formation, between the samples obtained after the first and the second extraction. Finally, it is noteworthy that CAR-UR extract showed a considerably greater capacity of inhibition with respect to CAR-R (Table 2).

Table 2. Percentage of inhibition and antioxidant activity of CAR-R and CAR-UR extracts.

\begin{tabular}{lcccccc}
\hline Sample & Series & Drying Time (h) & Extraction & \% Inhibition AGE & ORAC UNITS & \% Inhibition NO \\
\hline CAR-UR & UR1x & 24 & 1 & $35.32 \pm 0.02$ & $4.21 \pm 0.11$ & $30.0 \pm 0.98$ \\
CAR-UR & UR1y & 24 & 2 & $34.88 \pm 0.53$ & $3.43 \pm 0.3$ & $32.3 \pm 0.83$ \\
CAR-UR & UR2x & 48 & 1 & $34.93 \pm 0.16$ & $6.20 \pm 0.6$ & $28.3 \pm 0.42$ \\
CAR-UR & UR2y & 48 & 2 & $35.94 \pm 0.19$ & $7.23 \pm 0.23$ & $26.3 \pm 0.63$ \\
CAR-UR & UR3x & 72 & 1 & $38.17 \pm 0.15$ & $6.23 \pm 0.66$ & $23.4 \pm 0.11$ \\
CAR-UR & UR3y & 72 & 2 & $38.43 \pm 0.22$ & $13.28 \pm 0.03$ & $25.4 \pm 0.45$ \\
CAR-R & R1x & 24 & 1 & N.D. & $17.61 \pm 0.76$ & $30.7 \pm 0.37$ \\
CAR-R & R1y & 24 & 2 & $3.86 \pm 0.86$ & $2.75 \pm 0.25$ & $30.2 \pm 0.02$ \\
CAR-R & R2x & 48 & 1 & $1.88 \pm 0.1$ & $1.25 \pm 0.03$ & $32.0 \pm 0.66$ \\
CAR-R & R2y & 48 & 2 & N.D. & $13.47 \pm 0.14$ & $30.5 \pm 0.54$ \\
CAR-R & R3x & 72 & 1 & N.D. & $15.77 \pm 0.54$ & $40.7 \pm 0.47$ \\
CAR-R & R3y & 72 & 2 & $2.07 \pm 0.2$ & $13.96 \pm 0.33$ & $30.0 \pm 0.04$ \\
\hline
\end{tabular}

ORAC Units: Trolox equivalents for $\mu \mathrm{M}$ of sample; Trolox $=1$ Units ORAC; N.D. $=$ not detectable. Data represent the mean of three independent experiments \pm SD.

\subsubsection{ORAC Assay}

Free radicals and reactive oxygen species (ROS) are highly reactive molecules that are generated by normal cellular processes, ROS react with cellular components, damaging DNA, carbohydrates, proteins and lipids, causing cellular and tissue injury. ORAC assay measures antioxidant activity by hydrogen atom transfer, and it provides a comprehensive analysis of antioxidant activity. Therefore, it can be used to assay the antioxidant activity of natural compounds as candidate for therapeutic use, and it has been widely accepted as a standard in vitro method to measure the antioxidant activity. ORAC assay measures both lipophilic and hydrophilic antioxidant capacity, and determines the ability of antioxidants to protect proteins from damage caused by free radicals [37-39]. During the ORAC assay, the decay of the fluorescence of fluorescein was monitored. The loss of fluorescence over time is due to peroxyl-radical formation by the breakdown of AAPH (2,2'-azobis-2- methyl-propanimidamide, dihydrochloride) [21]. The ORAC assay has been used to determine the antioxidant activity of CAR-UR and CAR-R. In our experiments, the difference between "area under the fluorescence decay curve" (AUC) in the presence and absence of an antioxidant was expressed into a standard Trolox calibration curve to assess the antioxidant activity as a Trolox equivalent for $\mathrm{mg}$ (TE/mg) of the sample.

As reported in Table 2, CAR-R and CAR-UR extracts showed good ability for scavenging radicals according to the extraction time ( $24 \mathrm{~h}, 48 \mathrm{~h}$ and $72 \mathrm{~h}$ ), while no substantial differences between the samples obtained after the first and the second extraction were observed. A noteworthy CAR-R extract showed a higher ORAC activity with respect to CAR-UR sample. This result could be explained by the analysis of characterization data in Figure 3, showing the procyanidins quantification in both CAR-R and CAR-UR extracts. As reported in Figure 3, CAR-R samples were characterized by a higher procyanidins content with respect to CAR-UR extracts, probably due to a series of biochemical 
reactions associated to the different degree of ripening [40]. This evidence was corroborated by the characteristics of the ripe seeds, which showed a brown coloring; a typical index of a high procyanidin content [41] (Figure 6).

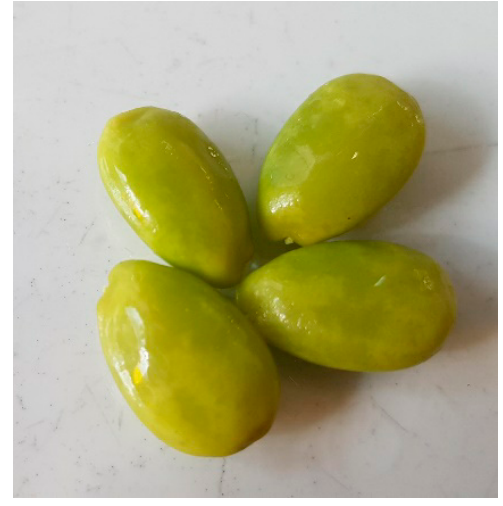

(a)

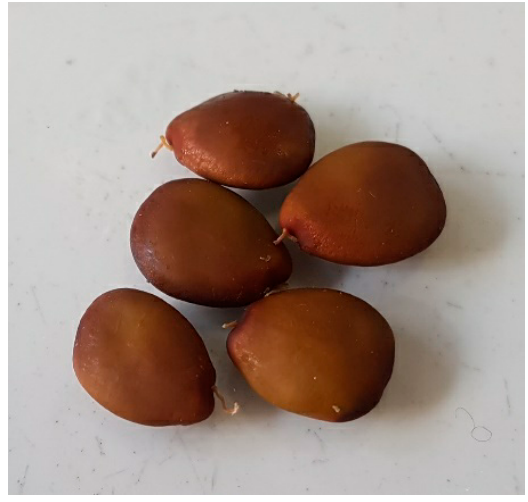

(b)

Figure 6. Color changes of carob seeds development. (a) Unripe and (b) ripe seeds.

Generally speaking, the fruit ripening involves a significant decrease of the phenolic compounds content, such as gallotannins, gallic acid and derivatives, catechins [42]. In the ripe carob, the decline of the phenolic content could be caused by the conversion of soluble phenolics into insoluble compounds and the oxidation of these compounds by polyphenol oxidase [43]. As reported in the literature [11], in the carob pods, the antioxidant activity decreases significantly from the unripe to ripe stage; these results are in agreement with the decline of phenolic content. Although the phenolic content decreases during ripening, our ORAC results relative the ripe extracts showed excellent antioxidant activity. This evidence is certainly attributable to the presence of procyanidins in the carob seeds, which, as previously mentioned, show a marked antioxidant activity and guarantee a remarkable sensitivity to the assay. Furthermore, these results could be attributed to the geographical origin $[43,44]$, the Sicilian variety and extraction conditions [45]. Finally, it is well known that polymeric procyanidins have the highest antioxidant activity following quercetin, catechins and gallic acid [42,46,47]. Therefore, procyanidins show a peculiar mechanism involved in the scavenger activity, which appears more suitable to ORAC assay.

\subsubsection{NO Scavenger Assay}

Nitric oxide is classified as a free radical, due to its unpaired electron, it exhibits remarkable reactivity with certain types of proteins and other free radicals such as ROS. Chronic exposure to the nitric oxide radical is associated with various pathological conditions, and its toxicity greatly increases when it reacts with the superoxide radical, forming the highly reactive peroxynitrite anion (ONOO-) and nitrogen dioxide $\left({ }^{*} \mathrm{NO}_{2}\right)$, which can irreversibly inhibit the mitochondrial transport chain, inducing oxidative stress and DNA mutations, and, at last, leading the cell to the apoptotic process. It has been shown that nitric oxide is directly countered by phytochemicals such as polyphenols. [48].

In Table 2, the nitric oxide inhibition capacity values for CAR-R and CAR-UR extracts are reported. The test was determined by inhibiting the spontaneous production of NO from an aqueous solution of sodium nitroprusside, as a NO donor, using Griess's reagent [23]. CAR-UR extracts show to possess a lower percentage of NO scavenger inhibition average $(27.62 \%)$ with respect to CAR-R samples showing an inhibition activity average of the nitric oxide equal to $32.3 \%$.

\section{Conclusions}

For centuries, carob fruit has been used in the food field and the seed fraction has been considered as food waste. Nowadays, there has been considerable attention toward the recovery of the waste plant 
matrices as possible sources of functional compounds with health properties. Therefore, our goal was the valorization of this fraction also in relation to the modification of its chemical composition during ripening. The extraction was carried out using a friendly extraction process UAE. This innovative method was able to maximize and preserve the quality of bioactive product [31]. Seed extracts of carob unripe (CAR-UR) and ripe (CAR-R) were characterized by HPLC and LC/MS for the content of bioactive polyphenols. Finally, they were analyzed by ORAC, NO and AGEs assays, in order to estimate the antioxidant potential of the active compounds. The obtained results showed an activity strongly affected by carob degree of ripening and, consequently, by the phytochemical composition of the seeds extracts, in particular the procyanidins content.

Author Contributions: D.S., C.P. and A.P.; methodology, G.G.; software, D.S.; G.R.; validation, C.G., A.P., D.S.; formal analysis, G.G.; investigation, G.G., C.G., D.S., A.P., E.A.S.; data curation, D.S., E.A.S., G.R.; writing-original draft preparation, C.G., G.G., D.S., A.P., C.P.; writing-review and editing, C.G., G.G., D.S., A.P., C.P.; supervision, C.P.; project administration, C.P. All authors have read and agreed to the published version of the manuscript.

Funding: This research received no external funding.

Acknowledgments: We thank Sandro Dattilo for LC-MS experiments.

Conflicts of Interest: The authors declare no conflict of interest.

\section{References}

1. Zhu, B.J.; Zayed, M.Z.; Zhu, H.X.; Zhao, J.; Li, S.P. Functional polysaccharides of carob fruit: A review. Chin. Med. 2019, 14, 40. [CrossRef] [PubMed]

2. Papaefstathiou, E.; Agapiou, A.; Giannopoulos, S.; Kokkinofta, R. Nutritional characterization of carobs and traditional carob products. Food Sci. Nutr. 2018, 6, 2151-2161. [CrossRef] [PubMed]

3. Fidan, H.; Stankov, S.; Petkova, N.; Petkova, Z.; Iliev, A.; Stoyanova, M.; Ivanova, T.; Zhelyazkov, N.; Ibrahim, S.; Stoyanova, A.; et al. Evaluation of chemical composition, antioxidant potential and functional properties of carob (Ceratonia siliqua L.) seeds. Food Sci. Technol. 2020, 57, 2404-2413. [CrossRef] [PubMed]

4. Goulas, V.; Stylos, E.; Chatziathanasiadou, M.V.; Mavromoustakos, T.; Tzakos, A.G. Functional Components of Carob Fruit: Linking the Chemical and Biological Space. Int. J. Mol. Sci. 2016, 17, 1875. [CrossRef]

5. Durazzo, A.; Turfani, V.; Narducci, V.; Azzini, E.; Maiani, G.; Carcea, M. Nutritional characterisation and bioactive components of commercial carobs flours. Food Chem. 2014, 153, 109-113. [CrossRef]

6. Turnbull, L.A.; Santamaria, L.; Martorell, T.; Rallo, J.; Hector, A. Seed size variability: From carob to carats. Biol. Lett. 2006, 2, 397-400. [CrossRef]

7. Zunft, H.J.; Lüder, W.; Harde, A.; Haber, B.; Graubaum, H.J.; Gruenwald, J. Carob pulp preparation for treatment of hypercholesterolemia. Adv. Ther. 2001, 18, 230-236. [CrossRef]

8. Avallone, R.; Cosenza, F.; Farina, F.; Baraldi, C.; Baraldi, M. Extraction and purification from Ceratonia siliqua of compounds acting on central and peripheral benzodiazepine receptors. Fitoterapia 2002, 73, 390-396. [CrossRef]

9. Corsi, L.; Avallone, R.; Cosenza, F.; Farina, F.; Baraldi, C.; Baraldi, M. Antiproliferative effects of Ceratonia siliqua L. on mouse hepatocellular carcinoma cell line. Fitoterapia 2002, 73, 674-684. [CrossRef]

10. Ahmed, M.M. Biochemical Studies on Nephroprotective Effect of Carob (Ceratonia siliqua L.) Growing in Egypt. J. Nat. Sci. 2010, 8, 41-47.

11. Benchikh, Y.; Louaileche, H.; George, B.; Merlin, A. Changes in bioactive phytochemical content and in vitro antioxidant activity of carob (Ceratonia siliqua L.) as influenced by fruit ripening. Ind. Crops Prod. 2014, 60, 298-303. [CrossRef]

12. Ghasemnezhad, M.; Sherafati, M.; Payvast, G.A. Variation in phenolic compounds, ascorbic acid and antioxidant activity of five coloured bell pepper (Capsicum annum) fruits at two different harvest times. J. Funct. Foods 2011, 3, 44-49. [CrossRef]

13. Ozcan, M.M.; Arslan, D.; Gökçalik, H. Some compositional properties and mineral contents of carob (Ceratonia siliqua) fruit, flour and syrup. Int. J. Food Sci. Nutr. 2007, 58, 652-658. [CrossRef] [PubMed]

14. Benković, M.; Bosiljkov, T.; Semić, A.; Ježek, D.; Srečec, S. Influence of Carob Flour and Carob Bean Gum on Rheological Properties of Cocoa and Carob Pastry Fillings. Foods 2019, 8, 66. [CrossRef] [PubMed] 
15. Hsouna, A.B.; Trigui, M.; Jarraya, R.M.; Damak, M.; Jaoua, S. Identification of phenolic compounds by high performance liquid chromatography/mass spectrometry (HPLC/MS) and in vitro evaluation of the antioxidant and antimicrobial activities of Ceratonia siliqua leaves extracts. J. Med. Plants Res. 2015, 9, 479-485. [CrossRef]

16. Rached, I.; Barros, L.; Fernandes, I.P.; Santos-Buelga, C.; Rodrigues, A.E.; Ferchichi, A.; Barreiro, M.F.; Ferreira, I.C.F.R. Ceratonia siliqua L. hydroethanolic extract obtained by ultrasonication: Antioxidant activity, phenolic compounds profile and effects in yogurts functionalized with their free and microencapsulated forms. Food Funct. 2016, 7, 1319-1328. [CrossRef] [PubMed]

17. Papagiannopoulos, M.; Wollseifen, H.R.; Mellenthin, A.; Haber, B.; Galensa, R. Identification and quantification of polyphenols in carob fruits (Ceratonia siliqua L.) and derived products by HPLC-UV-ESI/MSn. J. Agric. Food Chem. 2004, 52, 3784-3791. [CrossRef]

18. Derbré, S.; Gatto, J.; Pelleray, A.; Coulon, L.; Séraphin, D.; Richomme, P. Automating a 96-well microtiter plate assay for identification of AGEs inhibitors or inducers: Application to the screening of a small natural compounds library. Anal. Bioanal. Chem. 2010, 398, 1747-1758. [CrossRef]

19. Lauro, M.R.; Crascì, L.; Giannone, V.; Ballistreri, G.; Fabroni, S.; Sansone, F.; Rapisarda, P.; Panico, A.M.; Puglisi, G. An alginate/cyclodextrin spray drying matrix to improve shelf life and antioxidant efficiency of a blood orange by-product extract rich in polyphenols: MMPs inhibition and antiglycation activity in dysmetabolic diseases. Oxid. Med. Cell. Longev. 2017, 2017, 2867630. [CrossRef]

20. Cao, G.; Alessio, H.M.; Cutler, R.G. Oxygen-radical absorbance capacity assay for antioxidants. Free Radic. Biol. Med. 1993, 14, 303-311. [CrossRef]

21. Ou, B.; Hampsch-Woodill, M.; Prior, R.L. Development and validation of an improved oxygen radical absorbance capacity assay using fluorescein as the fluorescent probe. J. Agric. Food Chem. 2001, 49, 4619-4626. [CrossRef] [PubMed]

22. Montenegro, L.; Panico, A.M.; Santagati, L.M.; Siciliano, E.A.; Intagliata, S.; Modica, M.N. Solid lipid nanoparticles loading idebenone ester with pyroglutamic acid: In vitro antioxidant activity and in vivo topical efficacy. Nanomaterials 2019, 9, 43. [CrossRef] [PubMed]

23. Marcocci, L.; Maguire, J.J.; Droy-lefaix, M.T.; Packer, L. The nitric oxide-scavenging properties of Ginkgo biloba extract EGb 761. Biochem. Biophys. Res. Commun. 1994, 201, 748-755. [CrossRef] [PubMed]

24. Chaudhuri, D.; Ghate, N.B.; Sarkar, R.; Mandal, N. Phytochemical analysis and evaluation of antioxidant and free radical scavenging activity of Withania somnifera root. Asian J. Pharm. Clin. Res. 2012, 5, 193-199.

25. Crascì, L.; Cardile, V.; Longhitano, G.; Nanfitò, F.; Panico, A. Anti-degenerative effect of Apigenin, Luteolin and Quercetin on human keratinocyte and chondrocyte cultures: SAR evaluation. Drug Res. 2018, 68, 132-138. [CrossRef] [PubMed]

26. Esposito, E.; Ravani, L.; Mariani, P.; Contado, C.; Drechsler, M.; Puglia, C.; Cortesi, R. Curcumin containing monoolein aqueous dispersions: A preformulative study. Mater. Sci. Eng. C Mater. Biol. Appl. 2013, 33, 4923-4934. [CrossRef]

27. Esposito, E.; Ravani, L.; Mariani, P.; Huang, N.; Boldrini, P.; Drechsler, M.; Valacchi, G.; Cortesi, R.; Puglia, C. Effect of nanostructured lipid vehicles on percutaneous absorption of curcumin. Eur. J. Pharm. Biopharm. 2014, 86, 121-132. [CrossRef]

28. Mason, T.J.; Paniwnyk, L.; Lorimer, J.P. The uses of ultrasound in food technology. Ultrason. Sonochem. 1996, 3, S253-S260. [CrossRef]

29. Chemat, F.; Zill-e-Huma; Khan, M.K. Applications of ultrasound in food technology: Processing, preservation and extraction. Ultrason. Sonochem. 2011, 18, 813-835. [CrossRef]

30. Galanakis, C.M. Emerging technologies for the production of nutraceuticals from agricultural by-products: A viewpoint of opportunities and challenges. Food Bioprod. Process. 2013, 91, 575-579. [CrossRef]

31. Chemat, F.; Vian, M.A.; Cravotto, G. Green extraction of natural products: Concept and principles. Int. J. Mol. Sci. 2012, 13, 8615-8627. [CrossRef] [PubMed]

32. Pingret, D.; Fabiano-Tixier, A.S.; Bourvellec, C.L.; Renard, C.M.G.C.; Chemat, F. Lab and pilot-scale ultrasound-assisted water extraction of polyphenols from apple pomace. J. Food Eng. 2012, 111, 73-81. [CrossRef]

33. Lianfu, Z.; Zelong, L. Optimization and comparison of ultrasound/microwave assisted extraction (UMAE) and ultrasonic assisted extraction (UAE) of lycopene from tomatoes. Ultrason. Sonochem. 2008, 15, 731-737. [CrossRef] [PubMed] 
34. Pradal, D.; Vauchel, P.; Decossin, S.; Dhulster, P.; Dimitrov, K. Kinetics of ultrasound-assisted extraction of antioxidant polyphenols from food by-products: Extraction and energy consumption optimization. Ultrason. Sonochem. 2016, 32, 137-146. [CrossRef]

35. Dimitrov, K.; Kriaa, K.; Hadrich, B.; Kechaou, N.; Nikov, I. Kinetics of ultrasound assisted extraction of polyphenols from vegetal sources. Ars Separatoria 2010. In Proceedings of the XXVth International Symposium on Physico-Chemical Methods of Separation, Torun, Poland, 4-7 July 2010.

36. Crascì, L.; Lauro, M.R.; Puglisi, G.; Panico, A. Natural antioxidant polyphenols on inflammation management: Antiglycation activity vs metalloproteinases inhibition. Crit. Rev. Food Sci. Nutr. 2018, 58, 893-904. [CrossRef]

37. Gallardo, E.; Palma-Valdés, R.; Sarriá, B.; Gallardo, I.; de la Cruz, J.P.; Bravo, L.; Mateos, R.; Espartero, J.L. Synthesis and antioxidant activity of alkyl nitroderivatives of hydroxytyrosol. Molecules 2016, $21,656$. [CrossRef]

38. Leonardi, A.; Crascì, L.; Panico, A.; Pignatello, R. Antioxidant activity of idebenone-loaded neutral and cationic solid-lipid nanoparticles. Pharm. Dev. Technol. 2015, 20, 716-726. [CrossRef]

39. Lauro, M.R.; Crascí, L.; Sansone, F.; Cardile, V.; Panico, A.M.; Puglisi, G. Development and in vitro evaluation of an innovative dietary flavonoid supplement on osteoarthritis process. Oxid. Med. Cell. Longev. 2017, 2017, 7503240. [CrossRef]

40. Brahem, M.; Renard, C.M.G.C.; Bureau, S.; Watrelot, A.A.; Le Bourvellec, C. Pear ripeness and tissue type impact procyanidin-cell wall interactions. Food Chem. 2019, 275, 754-762. [CrossRef]

41. Malien-Aubert, C.; Dangles, O.; Amiot, M.J. Influence of procyanidins on the color stability of oenin solutions. J. Agric. Food Chem. 2002, 50, 3299-3305. [CrossRef]

42. Shi, Q.; Zhang, Z.; Su, J.; Zhou, J.; Li, X. Comparative Analysis of Pigments, Phenolics, and Antioxidant Activity of Chinese Jujube (Ziziphus jujuba Mill.) during Fruit Development. Molecules 2018, $23,1917$. [CrossRef] [PubMed]

43. Gull, J.; Sultana, B.; Anwar, F.; Naseer, R.; Ashraf, M.; Ashrafuzzaman, M. Variation in antioxidant attributes at three ripening stages of guava (Psidium guajava L.) fruit from different geographical regions of Pakistan. Molecules 2012, 17, 3165-3180. [CrossRef] [PubMed]

44. Soufi, O.; Romero, C.; Louaileche, H. Ortho-diphenol profile and antioxidantactivity of Algerian black olive cultivars: Effect of dry salting process. Food Chem. 2014, 157, 504-510. [CrossRef] [PubMed]

45. Vongsak, B.; Sithisarn, P.; Mangmool, S.; Thongpraditchote, S.; Wongkrajang, Y.; Grit-sanapan, W. Maximizing total phenolics, total flavonoids contents andantioxidant activity of Moringa oleifera leaf extract by the appropriate extractionmethod. Ind. Crop. Prod. 2013, 44, 566-571. [CrossRef]

46. Es-Safi, N.E.; Guyot, S.; Ducrot, P.H. NMR, ESI/MS, and MALDI-TOF/MS Analysis of Pear Juice Polymeric Proanthocyanidins with Potent Free Radical Scavenging Activity. J. Agric. Food Chem. 2006, 54, 6969-6977. [CrossRef]

47. Spranger, I.; Sun, B.; Mateus, A.M.; de Freitas, V.; Ricardo-da-Silva, J.M. Chemical characterization and antioxidant activities of oligomeric and polymeric procyanidin fractions from grape seeds. Food Chem. 2008, 108, 519-532. [CrossRef]

48. Luiking, Y.C.; Engelen, M.P.; Deutz, N.E. Regulation of nitric oxide production in health and disease. Curr. Opin. Clin. Nutr. Metab. Care 2010, 13, 97-104. [CrossRef]

Publisher's Note: MDPI stays neutral with regard to jurisdictional claims in published maps and institutional affiliations.

(C) 2020 by the authors. Licensee MDPI, Basel, Switzerland. This article is an open access article distributed under the terms and conditions of the Creative Commons Attribution (CC BY) license (http://creativecommons.org/licenses/by/4.0/). 